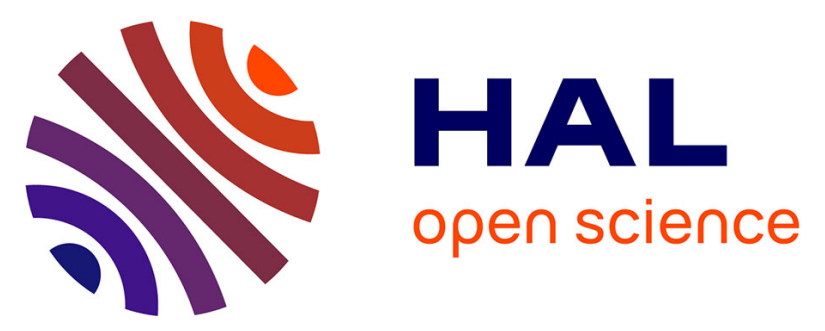

\title{
Laboratory studies of the adsorption of two pesticides (diuron and tebuconazole) using a batch design and an experimental flume: influence of contact conditions
}

\author{
O. Boutron, C. Margoum, J.M. Chovelon, C. Guillemain, V. Gouy
}

\section{- To cite this version:}

O. Boutron, C. Margoum, J.M. Chovelon, C. Guillemain, V. Gouy. Laboratory studies of the adsorption of two pesticides (diuron and tebuconazole) using a batch design and an experimental flume: influence of contact conditions. International Journal of Environmental Analytical Chemistry, 2010, 90 (3-6), p. 286 - p. 298. 10.1080/03067310903353487 . hal-00561006

\author{
HAL Id: hal-00561006 \\ https://hal.science/hal-00561006
}

Submitted on 31 Jan 2011

HAL is a multi-disciplinary open access archive for the deposit and dissemination of scientific research documents, whether they are published or not. The documents may come from teaching and research institutions in France or abroad, or from public or private research centers.
L'archive ouverte pluridisciplinaire HAL, est destinée au dépôt et à la diffusion de documents scientifiques de niveau recherche, publiés ou non, émanant des établissements d'enseignement et de recherche français ou étrangers, des laboratoires publics ou privés. 


\section{Laboratory studies of the adsorption of two pesticides (diuron and tebuconazole) using a batch design and an experimental flume: influence of contact conditions}

Olivier Boutron ${ }^{\star 1,2}$, Christelle Margoum ${ }^{1}$, Jean-Marc Chovelon², Céline Guillemain ${ }^{1}$ and Véronique Gouy ${ }^{1}$

${ }^{1}$ Cemagref, Groupement de Lyon, Unité Qualité des Eaux et Prévention des Pollutions, 3 bis Quai Chauveau, 69336 Lyon Cedex 09, France.

${ }^{2}$ Institut de Recherches sur la Catalyse et l'Environnement de Lyon (UMR CNRS/Université Claude Bernard Lyon1 5256), 2 Avenue A. Einstein, 69626 Villeurbanne Cedex, France.

* Corresponding author. Phone: 33674075228

E-mail: oboutron@yahoo.fr 


\section{Abstract}

The adsorption of two commonly used pesticides, diuron and tebuconazole, on an organic substrate (hemp), which was chosen as an analogue for natural substrates often found in agricultural ditches, has been studied using three different contact schemes: 1) contact in a beaker using a modified batch method; 2) contact in an experimental flume, with a dry start substrate; and 3) same as 2) but with the substrate initially saturated with water. Changes in pesticides concentrations as a function of time as well as adsorption after seven hours have been determined for each case. The highest adsorption is observed for the experiments with a flume initially containing dry hemp. In that case, both the initial condition (hemp initially without water) and the contact conditions between the pesticide solution and the substrate appear to favour adsorption. The lowest adsorption is obtained for the flume containing hemp initially saturated with water. In that case, samples that were obtained at different depths inside the hemp using capillary tubes showed that only the superficial part of the hemp was in equilibrium with the surface water. The presence of an initial water table appears to be a limiting factor for pesticides penetration and further adsorption onto hemp. An intermediate adsorption is obtained for the modified batch method. These results highlight the pronounced influence on adsorption of both the initial hemp humidity conditions and the contact conditions between the pesticides solution and the substrate. This influence should be studied further to assess the potential of agricultural ditches to mitigate pesticides contamination in surface water.

Key words: Pesticides, Diuron, Tebuconazole, Adsorption, Contact conditions, Agricultural Ditches, Experimental flume, Hemp.

\section{Introduction}

The intensification of agriculture has led to a diffuse contamination source for surface and ground waters by various pesticides [1-4]. Once pesticides are applied to a plot, they can be transferred through the soil and different landscape components before reaching the water courses. Of particular importance are farm ditches, which play a major role in the collection and transfer of water from agricultural plots. The fluxes of pesticides through ditches can be modified by a number of physical, chemical or biological processes which can contribute to the reduction of the amount of pesticides reaching the rivers [5-9]. Pesticides adsorption onto ditch substrates is a very interesting process for 
the mitigation of surface water contamination, the efficiency of which is poorly understood. The pesticides adsorption that occurs during water flows in natural ditches is not easy to predict, as it depends upon the adsorption capacities of the substrates which are present at the bottom of the ditches and the capacity of the pesticides to reach the reactive sites of the substrate, mainly by hydraulic transport.

This study is aimed at evaluating the influence of various contact conditions on the adsorption of two pesticides onto a standard of ditch substrate under controlled conditions. Special attention was given to the influence of the initial conditions (dry or water saturated substrate) and water dynamics. We studied the adsorption kinetics and the adsorption at equilibrium which are observed for three different contact schemes: 1) contact in a glass beaker using a modified batch method ; 2) contact in a recirculating experimental flume, in which the substrate covers the bottom part of the flume and is initially without water ; 3) same as 2) but with a substrate initially saturated with pesticide free water. The comparison of the data obtained with schemes 1) (where the transfer of the pesticides onto and inside the substrate assisted by orbital shaking of the beaker) and 2) (where the transfer of the pesticides is linked to the flow in the flume) allowed us to evaluate the influence of the water dynamics. The comparison of the data obtained by schemes 2) and 3) allowed us to test the influence of the presence of water inside the substrate at the start of the experiment (using initially dry or water saturated substrate). Schemes 2) and 3) were designed to mimic the contact conditions that are commonly encountered in ephemeral ditches, those in which the substrate dries out between successive water flow events, and those with a permanent water flow.

The use of an experimental flume was selected to overcome the difficulties encountered with field studies, which make it difficult to establish quantitative balances. In addition, when considering the wide diversity of substrates that are found at the bottom of agricultural ditches [10] (typically living and/ or dead plants, with various decomposition levels, or sediments), and any possible changes in their characteristics over time, we have decided to use a simplified organic substrate made of hemp fibres, as discussed in detail in refs [11-12]. 


\section{Experimental}

\subsection{Pesticides}

Two pesticides, diuron (3-(3,4-dichlorophenyl)-1,1-dimethylurea) and tebuconazole ((RS)-1-pchlorophenyl-4,4-dimethyl-3-(1H-1,2,4-triazol-1-ylmethyl)pentan-3-ol) were selected because they have been extensively used in agricultural plots and are commonly found in surface waters. They are characterized by a wide range of physico-chemical properties as shown in Table 1, so that various behaviours can be expected for their adsorption onto the substrate. The commercial formulations Zodiac TX (diuron) and Folicur $250 \mathrm{EW}$ (Tebuconazole) from Bayer Crop Science were used. In addition, potassium bromide was added as a tracer for water transport through the substrate.

\subsection{Substrate}

We have used hemp fibres as a standard for the natural vegetation based substrates that can be found in agricultural ditches. They were obtained as rolls (with a thickness of $10 \mathrm{~cm}$ ) from Chanvre et Technique, Riec sur Belon, France (Technichanvre trade mark), see Figure 1. They are made of $85 \%$ of hemp fibres, mixed with $15 \%$ of polyester fibres in order to obtain adequate mechanical properties, especially regarding their geometry stability over long time periods. A number of relevant physical and chemical parameters for this substrate have been determined, in collaboration with Nathalie TouzeFoltz and Rolland Gallo from Cemagref Antony. These fibres have the following physical characteristics: a porosity of 0.38 , a vertical conductivity (i.e. through the thickness of the roll) of 3.4 $\mathrm{cm} . \mathrm{s}^{-1}$ and a longitudinal conductivity (i.e. through the length of the roll) of $3.1 \mathrm{~cm} \cdot \mathrm{s}^{-1}$. The density is 25 $\mathrm{kg} \cdot \mathrm{m}^{-3}$ and the specific area is $1.07 \mathrm{~m}^{2} \cdot \mathrm{g}^{-1}$. The mean elementary composition is as follows: C: $45.44 \% ; \mathrm{H}: 6.02 \% ; \mathrm{N}: 0.35 \% ; \mathrm{O}: 46.98 \%$. 


\subsection{Modified batch adsorption experiments}

Adsorption experiments were performed using the modified batch technique as described by Margoum et al. [13]. A piece of hemp roll $(5 \mathrm{~g})$ was placed in a glass beaker with $250 \mathrm{~mL}$ of an aqueous solution containing the two pesticides at a concentration of $20 \mu \mathrm{g} / \mathrm{L}$ and bromide at a concentration of 100 $\mathrm{mg} / \mathrm{L}$. The solution was prepared using deionized water containing $\mathrm{NaCl}(5 \mathrm{mM})$ and $\mathrm{NaHCO}_{3}(4 \mathrm{mM})$. The $\mathrm{pH}$ was typically 7.5 (see ref [11]). The beaker was covered with a Petri dish to avoid evaporation and was gently shaken for 7 hours (50 rpm - orbital mixer STR, Stuart Scientific) at room temperature (Figure 2). Triplicate water samples were taken at different intervals during the 7 hour period, in order to determine the adsorption kinetics. Control samples without substrate, and pesticide free blanks were also analyzed. No pesticide degradation or sorption onto the glass beaker walls were observed. The initial concentration of $20 \mu \mathrm{g} / \mathrm{L}$ for the two pesticides was chosen as a good compromise between the typical concentrations found at the edge of agricultural plots (see e.g. [14]) and the minimization of analytical uncertainties.

\subsection{Experimental flume}

The experimental flume (Figure 3) was $730 \mathrm{~cm}$ long and had a $40 \mathrm{~cm}$ wide channel. The flume and all the recirculation pipes were made of PVC. However, one lateral wall was made of Plexiglas to permit flow visualization. The hemp rolls were on the bottom of the flume, and covered the entire bottom surface. The flume allows the control of the water speed and depth, and recirculates the water to increase the contact time. As shown in Figure 3, a mixing tank was added to homogenise the concentration of the pesticides in the water solution. A flowmeter and a stabilization tank are necessary to prevent the occurrence of eddies at the entrance of the flume, and are placed upstream of the flume itself. The water depth in the flume is fixed using an impermeable end-plate. Preliminary experiments showed that the impermeable ends did not provide very good end conditions. A slim box was then installed at each end of the flume (see Figure 3). The boxes were closed except one vertical face of each boxe which was covered by a stainless steel mesh. The subsurface flow passed through the mesh and was recirculated from the end of the flume to the inlet by means of a peristaltic pump. Two vertical cross sections of the hemp were equipped with capillary tubes to determine the penetration depths of the pesticides, see Figure 3.

The experimental duration was 7 hours. For experiments with the hemp initially saturated in water, the flume was filled at the beginning of the experiment with the deionized water in which $5 \mathrm{mM}$ of $\mathrm{NaCl}$ 
and $4 \mathrm{mM}$ of $\mathrm{NaHCO}_{3}$ had been added. For the experiments with hemp initially without water, the flume was left dry. In both cases, a solution containing the two pesticides and bromide was prepared in the mixing tank using deionized water with $5 \mathrm{mM}$ of $\mathrm{NaCl}$ and $4 \mathrm{mM}$ of $\mathrm{NaHCO}_{3}$ as a diluent, to obtain concentrations of $20 \mu \mathrm{g} / \mathrm{L}$ for the two pesticides and $100 \mathrm{mg} / \mathrm{L}$ for bromide in the surface water flow in the flume (after dilution in the case of the substrate initially saturated with water). Water samples were collected during the whole experiment at different time intervals downstream of the flume, at various points in the surface flow, and from each capillary tube to determine the pesticides and bromide concentrations. The water depth above the hemp surface and the speed of the surface water flow were also monitored. During the experiments, the surface water speed was kept to $3 \mathrm{~cm} / \mathrm{s}$, while the subsurface water speed was $0.03 \mathrm{~cm} / \mathrm{s}$ [11] and the water depth was kept at $2.5 \mathrm{~cm}$ [11]. These three parameters were kept constant during the experiments. Additional detailled information about the experiments can be found in ref [11].

\subsection{Pesticides and bromide determination}

Bromide concentrations were determined by lon Chromatography (Dionex DX-120 with a AS9-HC column) using direct injections (limit of detection: $0.2 \mathrm{mg} / \mathrm{L}$ ). For diuron and tebuconazole, the water samples were filtered using $0.2 \mu \mathrm{m}$ filters (Chromafil filters PET 20/15 MS, Macherey Nagel) and a $990 \mu \mathrm{L}$ aliquot was then transferred into an auto-sampler vial with $10 \mu \mathrm{L}$ of deutered diuron $\mathrm{D} 6$ as an internal standard. The samples were then analyzed using a high performance liquid chromatography instrument (Series 1100, Agilent Technologies) equipped with a 125-2 RP18e $5 \mu \mathrm{m}$ LichroCART column (Merck), coupled to a triple quadrupole mass spectrometer (API 4000, LC/MS/MS system, Applied Biosystems) with an ESI source. The injection volume was $100 \mu \mathrm{L}$ (with triplicate determinations). The limit of detection was $0.02 \mu \mathrm{g} / \mathrm{L}$ for diuron and $0.2 \mu \mathrm{g} / \mathrm{L}$ for tebuconazole. The analytical uncertainties were about $10 \%$. 


\section{Results and discussion}

\subsection{Comparison of the adsorption kinetics for schemes 1) and 2)}

The comparison of the experiments with schemes 1) (modified batch method) and 2) (dry hemp) allowed an investigation of the influence of the water dynamics on the adsorption of the pesticides. In both cases the solution of pesticides is in contact with the whole hemp volume at the beginning of the experiment (at introduction of the pesticides solution into the beaker or into the flume, which were initially dry). In addition, the mass of hemp / volume of water ratio was kept the same for both experiments.

Figure 4 shows changes in diuron, tebuconazole and bromide concentrations in water as a function of time for the batch experiments (contact scheme 1)). It is interesting to compare these data with those obtained for the flume with dry hemp (Figure 5a). For the flume experiments, equilibrium was reached after 7 hours. Conversely, equilibrium for the batch experiments was not reached after 7 hours (additional experiments over 48 hours showed that it was reached after about 24 hours).

For the two schemes, the transfer of the pesticide molecules into the whole volume of hemp was relatively easy at the start of the experiments, as the hemp was initially dry (see steps 1 and 2 in Figures 6 and 7), leading to the adsorption of a fraction of the pesticide molecules (see steps 2 and 3 in Figures 6 and 7). The pesticide molecules that remained outside the hemp were then transferred into the hemp via various mechanisms.

Tentatively, it can be assumed that this transfer is mainly linked to turbulent diffusion in the batch experiments (see step 4 in Figure 6), and to advection for the flume experiments [15-21] (see step 4 in Figure 7). Turbulent diffusion, which returns to a combination of molecular diffusion coupled with turbulence, is a process which is slower and less efficient than advection for the transfer of contaminants, this is in good agreement with the observed differences for the two experiments (see Figures 4 and 5a). It should however be kept in mind that for the batch experiments, turbulent diffusion is not homogeneous in the whole hemp volume because of orbital shaking, leading to stronger diffusion in the outer parts of the hemp and much weaker diffusion in the center (see step 4 in Figure 6). For the flume experiments, the situation is different, there is a rather homogeneous advection due to the use of two pumps (see step 4 in Figure 7). 
Our experiments indicate that it is necessary to take into account the water dynamics when assessing the adsorption kinetics of the pesticides. So when investigating the adsorption kinetics of pesticides in agricultural ditches, it will then be necessary to design experiments which reproduce the water dynamics in agricultural ditches for realistic field conditions, as example obtained with flume experiments.

3.2. Influence on the kinetics of adsorption of the presence of water in the hemp at the beginning of the experiments

The comparison of the data obtained with the experimental flume for schemes 2) (dry hemp) and 3) (saturated hemp) allows an evaluation of the influence on the adsorption kinetics of the presence of water at the beginning of the experiments. Figure 5 shows the changes in diuron, tebuconazole and bromide concentrations in water as a function of time for the contact schemes 2) (Figure 5a) and 3) (Figure $5 b$ ). It indicates that the adsorption kinetics is faster with initially dry hemp than for hemp initially saturated with water. For initially dry hemp, as soon as the water overflows above the downstream impermeable end-plate (after about 30 minutes), the $C / C_{0}$ ratio (where $C$ and $C_{0}$ represent the concentration of diuron or tebuconazole in the surface water flow determined at the downstream end of the flume and in the water at the beginning of the experiment, respectively) is very close to the equilibrium ratio value for the two pesticides. The whole hemp cross section is rapidly involved in the adsorption of the two pesticides since no water was present in the hemp at the beginning of the experiment (see steps 1 and 2 in Figure 7). The situation is different for hemp initially saturated with water, with equilibrium still not reached even after 7 hours. In this case, the penetration of the pesticides into the hemp is determined by the capillary tubes data, and is shown as increasing over time as illustrated by the observed changes in the penetration of diuron and tebuconazole into the hemp (Figures 8a,b). It can be seen that diuron and tebuconazole have not penetrated uniformly into hemp after 7 hours since they are mainly present in the upper layer of the hemp. Similar observations have already been made by Elliott and Brooks [17] for a sand bed and two fluorescent dye tracers. These data suggest that pesticides penetration into the lowest part of the hemp would probably continue to increase slowly after seven hours, but this would need to be confirmed by performing longer experiments. 


\subsection{Comparison of the adsorption after 7 hours for the different experiment schemes}

As bromide is not adsorbed onto hemp, the mass of pesticides adsorbed at the end of the experiments has been estimated from the difference between the mass of bromide and the mass of diuron or tebuconazole remaining in the aqueous solution after 7 hours, as explained in detail in ref [11].

Table 2 shows the percentages of the mass of diuron and tebuconazole adsorbed onto hemp after 7 hours for the three experimental schemes (the results are expressed as percentages of the initial mass of pesticide in water at the beginning of the adsorption experiment), with the same hemp / water mass / volume ratio for the three schemes. The adsorption for tebuconazole is larger than for diuron in all cases, which is in good agreement with their respective Koc values (see Table 1).

Table 2 shows that after 7 hours, contact scheme 2) (flume with dry hemp) gives the highest adsorption both for diuron and tebuconazole. These high adsorption values can be explained by the lack of water in the hemp at the beginning of the experiment and a rapid transfer of the pesticides into hemp, probably mainly by advection. Intermediate adsorption values are observed after 7 hours for the batch experiments, which also allow full contact of the pesticides solution with hemp, but with a transfer of the pesticides into hemp probably mainly by turbulent diffusion.

When comparing the adsorption at equilibrium for schemes 1) (equilibrium reached after 24 hours) and 2) (equilibrium reached after 7 hours), it appears that total adsorption is similar for the two schemes for tebuconazole while adsorption is lower for diuron with the batch experiment (Table 2). For diuron, this suggests that advection could favour both the adsorption kinetics and the adsorption at equilibrium, compared to turbulent diffusion, while it may only favour the adsorption kinetics for tebuconazole. It would be interesting to perform similar experiments for other pesticides to better assess the effect of these two processes on their adsorption at equilibrium.

Finally, the least favourable situation appears to be that for scheme 3) (flume initially saturated hemp), see Table 2. In this case, equilibrium is still not reached after 7 hours, and adsorption is linked to the penetration of pesticides into the hemp. It will be necessary to perform additional studies to investigate the influence of the water flow parameters on their penetration (especially the water depth and speed), the characteristics of the substrate (conductivity, porosity) and the shape of the interface between the 
substrate and the surface water flow. Similar studies have already been performed for other compounds and substrates, by Elliott and co-workers [15-17, 20, 21].

\section{Conclusion}

The aims of this study were to compare the adsorption of two pesticides onto a standard (hemp) for agricultural ditch substrate with different contact conditions, using three different experimental schemes. The first was adapted from a standard batch method (scheme 1)). For this first scheme the hemp was initially dry and the transfer of the pesticides into hemp was tentatively attributed to turbulent diffusion. The second and third schemes, based on an experimental flume, were designed to approach the field conditions as encountered for dry (scheme 2)) or wet agricultural ditches (scheme 3) ). In these last two schemes, the transfer of the pesticides into hemp was tentatively attributed to advection.

The highest adsorption was observed for schemes 1) and 2) with initially dry hemp, especially for scheme 2) which corresponds to the conditions typically encountered in the field in dry agricultural ditches. The highest adsorption observed for scheme 2) could tentatively be explained by the prevalence of advective transfer of the pesticides, compared to the predominance of turbulent diffusive transfer for scheme 1). Conversely, adsorption by hemp initially saturated with water was much less and is mainly linked to the limited penetration of the pesticides into the hemp during the experiments.

To improve the mitigation of pesticides in agricultural ditches, it seems important to favour ephemeral ditches in which the substrate remains dry between successive water flow events, and to favour the advective transfer of the pesticides into the bed substrate.

\section{Acknowledgements}

We wish to thank Nathalie Touze-Foltz and Rolland Gallo from Cemagref Antony for the determination of the conductivity and porosity of hemp, Francis Bereiziat, Nathalie Ball, Anne-Laure Achard and Sébastien Chaumat from Cemagref Lyon for their contribution to the experimental work and fruitful 
discussions, and Warren Cairns from CNR-IDPA /University Ca' Foscari in Venice for his various constructive comments on the manuscript.

\section{References}

[1] L. Guo, K. Kelley, and K.S. Goh, Environ. Toxicol. Chem. 26, 2274 (2007).

[2] IFEN, French Institute of Environment, Orléans, France, http://www.ifen.fr/ (2004).

[3] S. Jergentz, H. Mugni, C. Bonetto, and R. Schulz, Chemosphere. 61, 817 (2005).

[4] R.B. Zhou, L.Z. Zhu, and Y.Y. Chen, Environ. Monit. Assess. 136, 277 (2008).

[5] E.R. Bennett, M.T. Moore, C.M. Cooper, S. Smith, F.D. Shields, K.G. Drouillard, and R. Schulz, Environ. Toxicol. Chem. 24, 2121 (2005).

[6] C.M. Cooper, M.T. Moore, E.R. Bennett, S. Smith, J.L. Farris, C.D. Milam, and F.D. Shields, Water Sci. Technol. 49, 117 (2004).

[7] M.T. Moore, E.R. Bennett, C.M. Cooper, S. Smith, F.D. Shields, C.D. Milam, and J.L. Farris, Agric. Ecosyst. Environ. 87, 309 (2001).

[8] M.T. Moore, D.L. Denton, C.M. Cooper, J. Wrysinski, J.L. Miller, K. Reece, D. Crane, and P. Robins, J. Environ. Qual. 37, 486 (2008).

[9] R. Schulz, J. Environ. Qual. 33, 419 (2004).

[10] P. Lagacherie, O. Diot, N. Domange, V. Gouy, C. Floure, C. Kao, R. Moussa, J.M. Robbez-Masson, and V. Szleper, Ecol. Indic. 6, 265 (2006).

[11] O. Boutron, PhD. thesis, University Claude Bernard of Lyon, France, 2009.

[12] O. Boutron, V. Gouy, N. Touze-Foltz, P. Benoit, J.M. Chovelon, and C. Margoum, Geotextiles and Geomembranes. 27, 254 (2009).

[13] C. Margoum, C. Malessard, and V. Gouy, Chemosphere. 63, 1835 (2006).

[14] X. Louchart, M. Voltz, P. Andrieux, and R. Moussa, J. Environ. Qual. 30, 982 (2001).

[15] A.H. Elliott, PhD. thesis, California Institute of Technology, Pasadena, USA, 1990.

[16] A.H. Elliott and N.H. Brooks, Water Resour. Res. 33, 123 (1997). 
[17] A.H. Elliott and N.H. Brooks, Water Resour. Res. 33, 137 (1997).

[18] S.A. Savant, D.D. Reible, and L.J. thibodeaux, Water Resour. Res. 23, 1763 (1987).

[19] L.J. Thibodeaux and J.D. Boyle, Nature 325, 341 (1987).

[20] H. Eylers, PhD. thesis, California Institute of Technology, Pasadena, USA, 1994.

[21] S.M. Forman, PhD. thesis, California Institute of Technology, Pasadena, USA, 1998.

[22] INRA, available from : http://www.dive.afssa.fr/agritox/index.php (2007).

[23] C.D.S. Tomlin, The Pesticide Manual, (British Crop Protection Council, Farnham, UK, 2000).

[24] FOOTPRINT Pesticide Properties Database, available from : http://www.eufootprint.org/ppdb.html (2008)

\section{Figures Captions}

Figure 1. The rolls of hemp used in this study.

Figure 2. Modified batch adsorption experiment.

Figure 3. Schematic diagram of the flume. 1: mixing tank; 2: flowmeter; 3: upstream stabilization tank; 4: cross sections equipped with capillary tubes; 5: downstream subsurface flow discharge box; 6: peristaltic pump to recirculate subsurface flow; 7: upstream subsurface flow discharge box; 8: centrifugal pump. Hemp is shown with a brown color. Depending upon the experimental scheme, it is initially with water or without water.

Figure 4. Diuron, tebuconazole and bromide concentrations in water as a function of time for the batch experiments. The results are expressed as $C / C_{0}$, where $C$ represents the concentration of diuron, tebuconazole or bromide in the water at a given time, and $C_{0}$ the concentration of diuron, tebuconazole or bromide in the water at the beginning of the experiment. 
Figure 5. Diuron, tebuconazole and bromide concentrations in water as a function of time for two contact schemes using an experimental flume. (a) initially dry hemp and (b) initially saturated hemp (same mass of hemp / water volume ratio for the two schemes). The results are expressed as $C / C_{0}$. Where $C$ represents the concentration of diuron, tebuconazole or bromide in the surface water flow at the downstream end of the flume at a given time. For the flume experiments with initially dry hemp, $C_{0}$ represents the diuron, tebuconazole or bromide concentration in the water at the beginning of the experiment. For the flume experiments with hemp initially saturated with water, $C_{0}$ represents the concentration after dilution in the surface water flow.

Figure 6. Batch experiment. The diagrams show a top view of the beaker and the piece of hemp. (1) Introduction of the pesticides solution into the beaker (initially dry hemp). (2) Some of the pesticides molecules have already penetrated inside hemp. (3) Adsorption of some of the pesticides molecules onto hemp (illustrated by the disappearence of some of the black dots). (4) The clockwise shaking of the beaker creates a water motion in the beaker, which results in a transfer of the molecules of pesticides from the outside water to the bulk hemp mainly by turbulent diffusion. Because of the orbital shaking, turbulent diffusion is small in the center of hemp and greater in the outer parts of the hemp. Vertical motions of the water and molecules are not represented in the diagrams.

Figure 7. Flume experiment with the initially dry hemp. (1) Introduction of the pesticides solution into the flume. (2) Some of the pesticides molecules have already penetrated inside hemp. (3) Adsorption of some of the pesticides molecules onto the hemp (illustrated by the disappearence of some of the black dots). (4) Because of the high surface water flow and the weaker lateral water flow inside the hemp, the molecules of pesticides that are present in the surface water flow penetrate into hemp mainly by advection. Inside the hemp, the transfer of these molecules is mainly by advection.

Figure 8. Penetration of diuron (a) and tebuconazole (b) into hemp initially saturated with water as a function of time. The results are expressed as $C_{c} / C_{s}$, where $C_{c}$ represents the concentration of diuron or tebuconazole in the water sample collected with a capillary tube for a given depth while $C_{S}$ represents the concentration of diuron or tebuconazole measured in the surface water flow. Open squares: surface down to $3.3 \mathrm{~cm}$; black triangles: 3.3 to $6.6 \mathrm{~cm}$; open circles: 6.6 to $10 \mathrm{~cm}$. The values shown on the figure are averages of the different $C_{d} / C_{S}$ values measured at the two sections equipped with capillary tubes. 

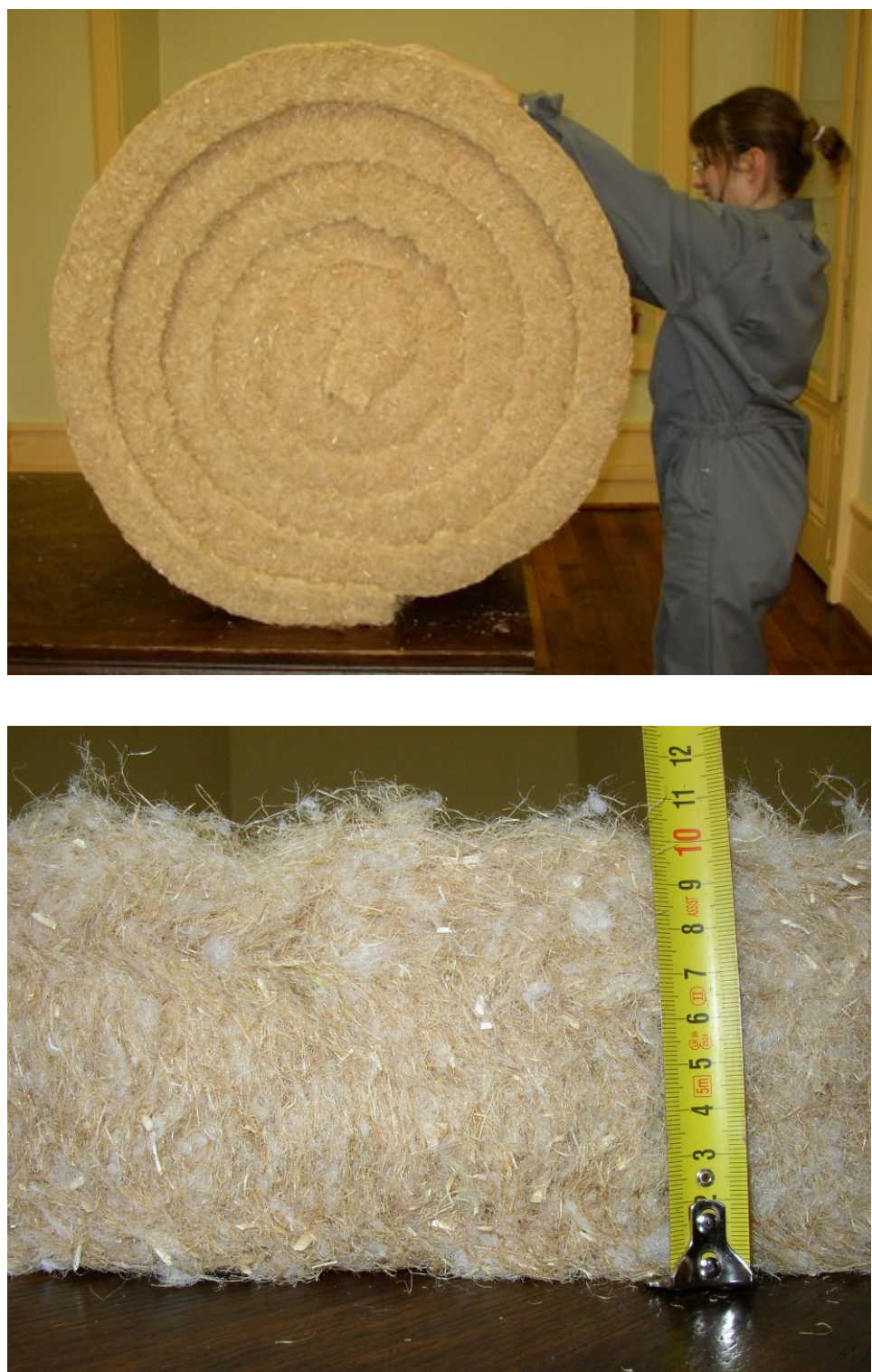

Figure 1. 
International Journal of Environmental Analytical Chemistry, 90, 3-6, 286-298, doi:10.1080/03067310903353487

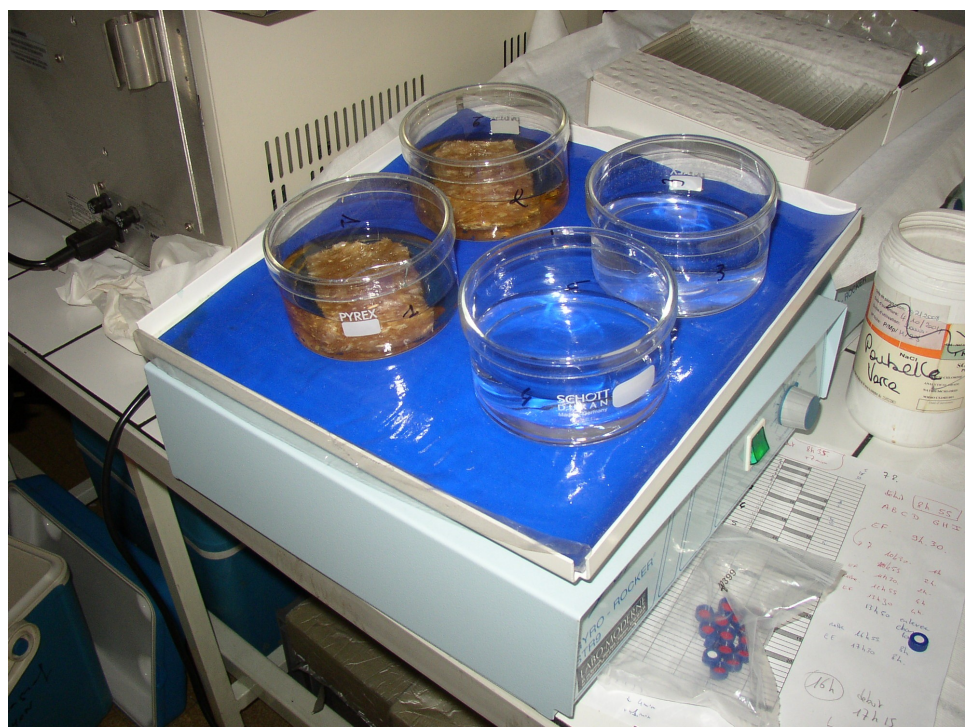

Figure 2. 


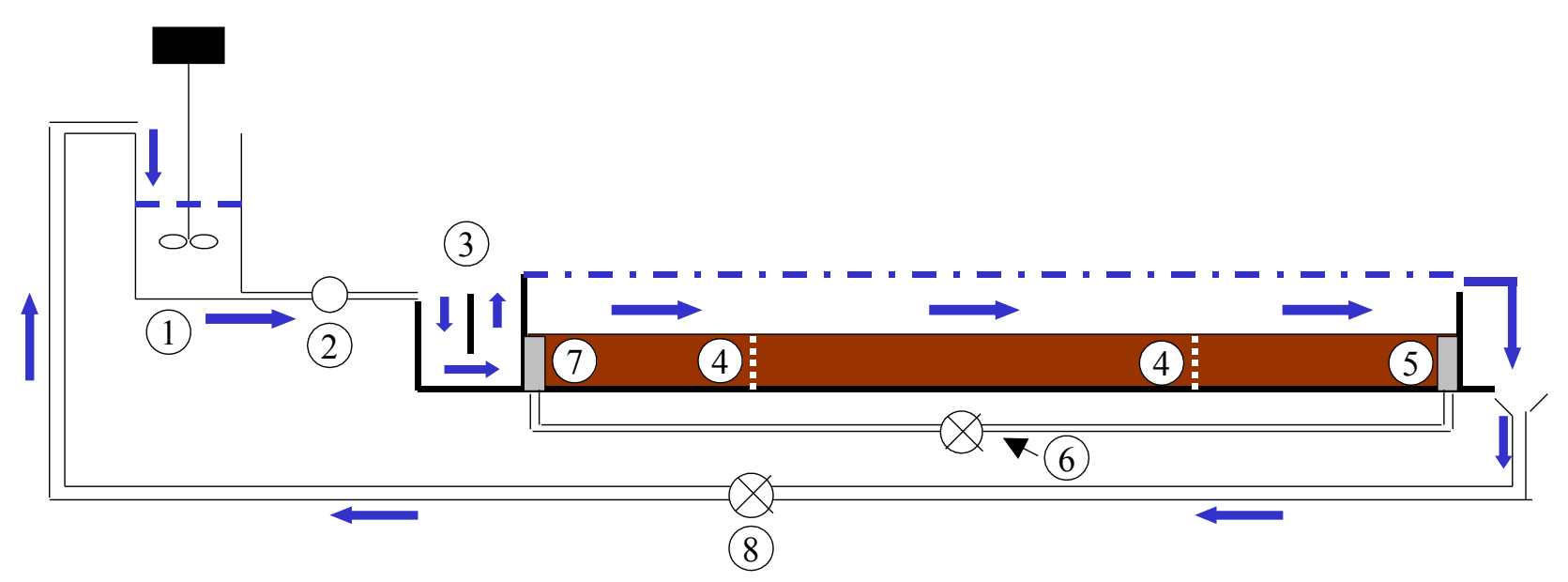

Figure 3. 


\section{Batch experiment}

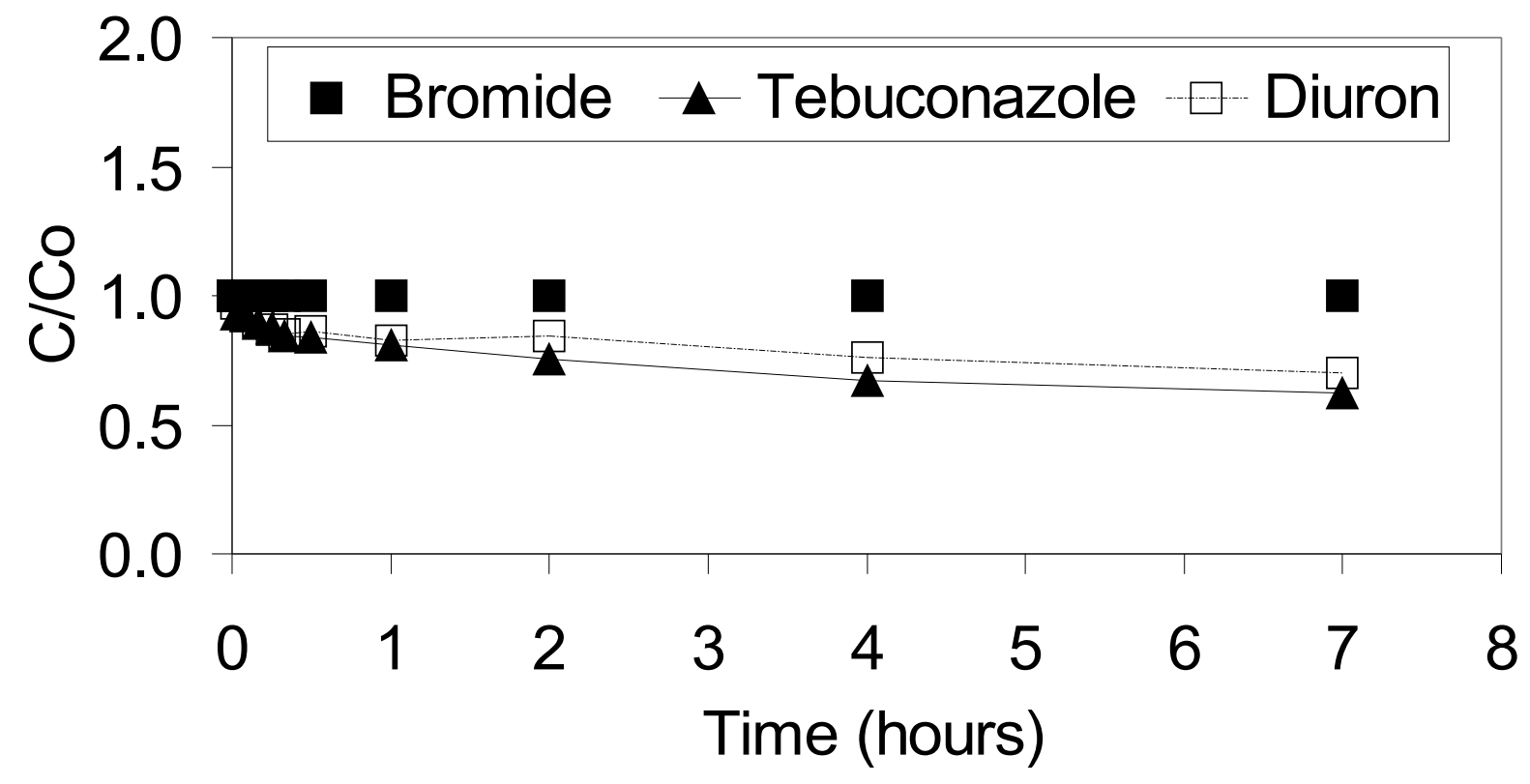

Figure 4. 
(a): Hemp initially without water

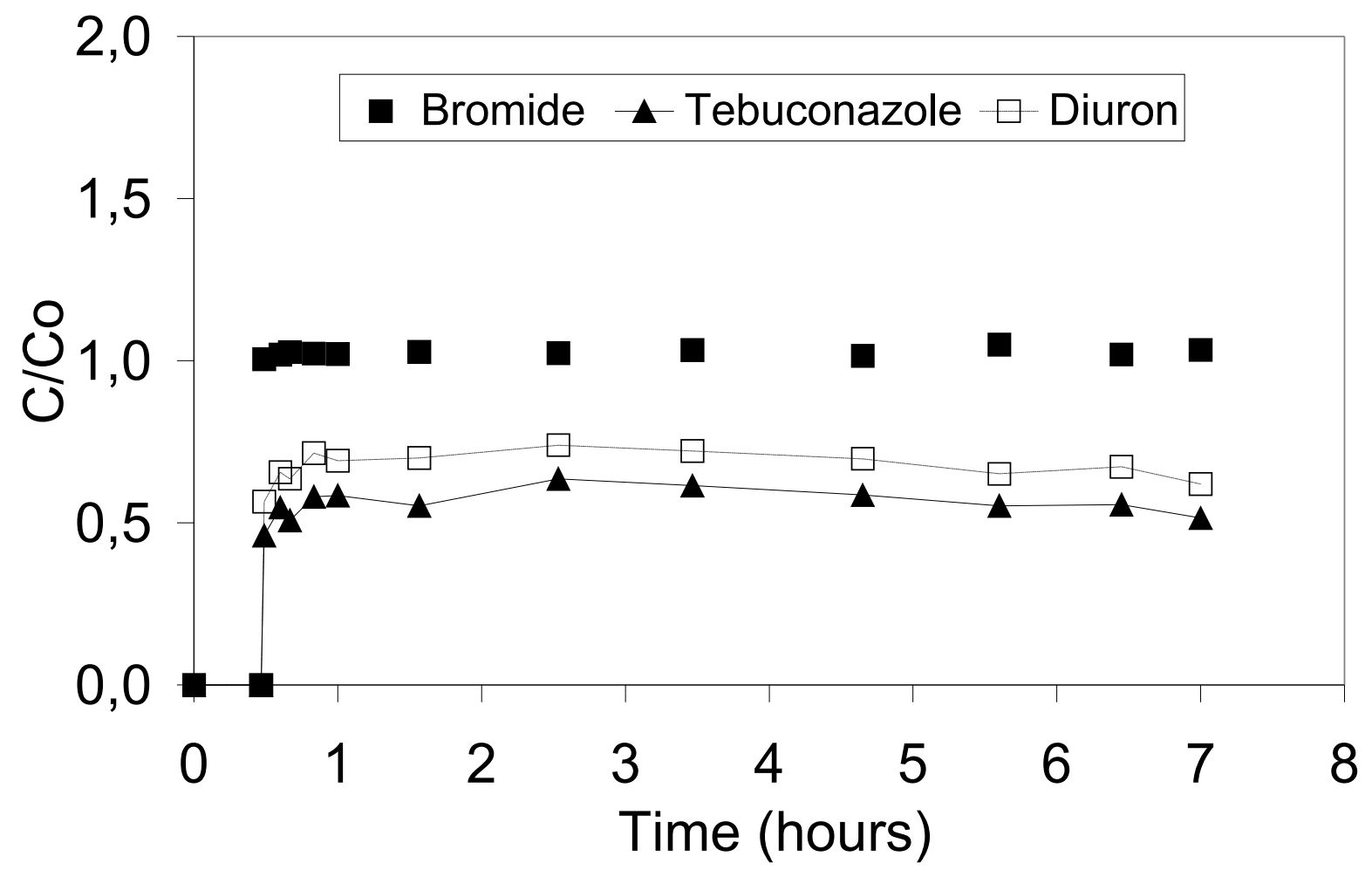


(b): Hemp initially saturated with water

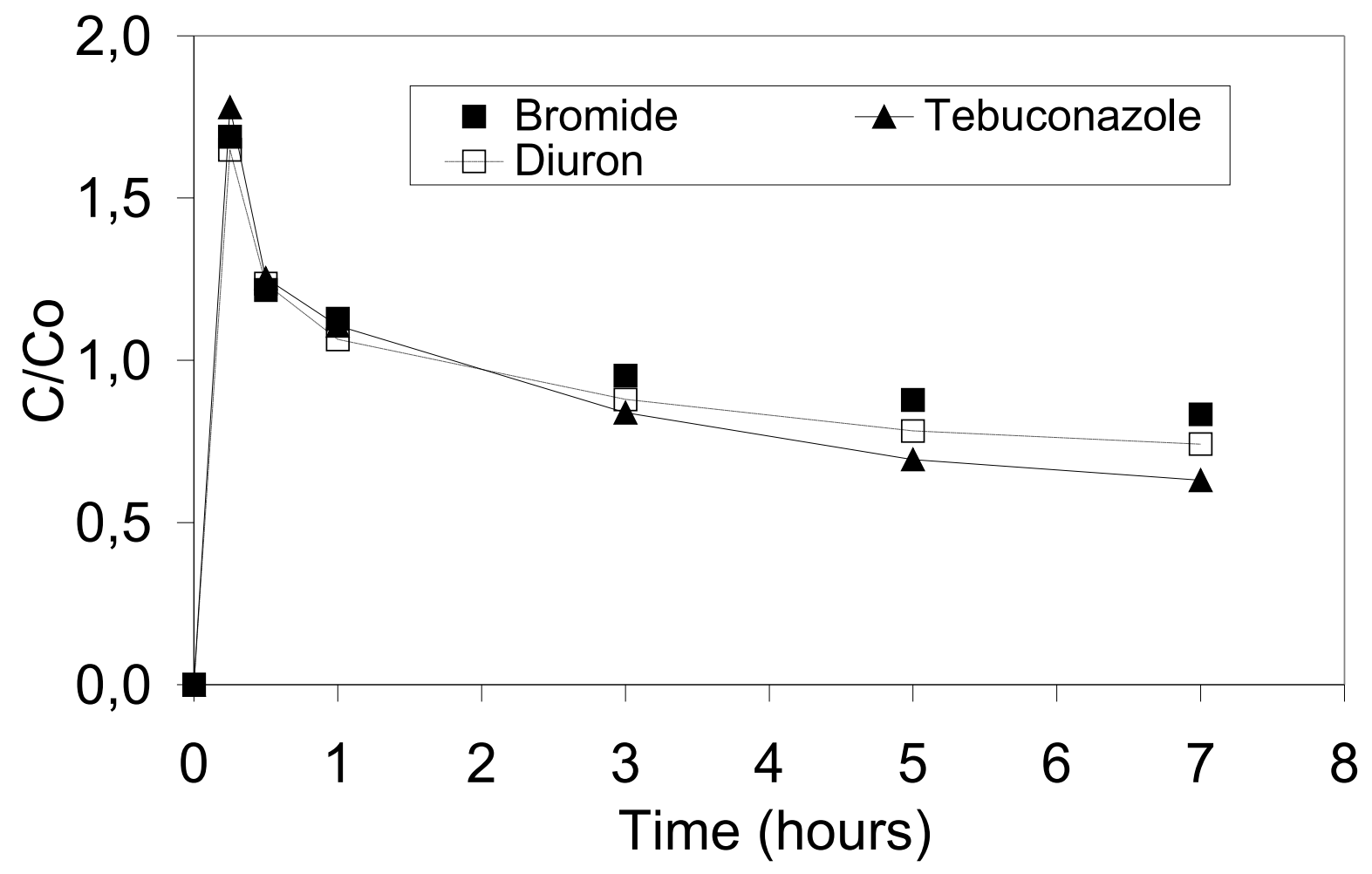

Figure 5. 


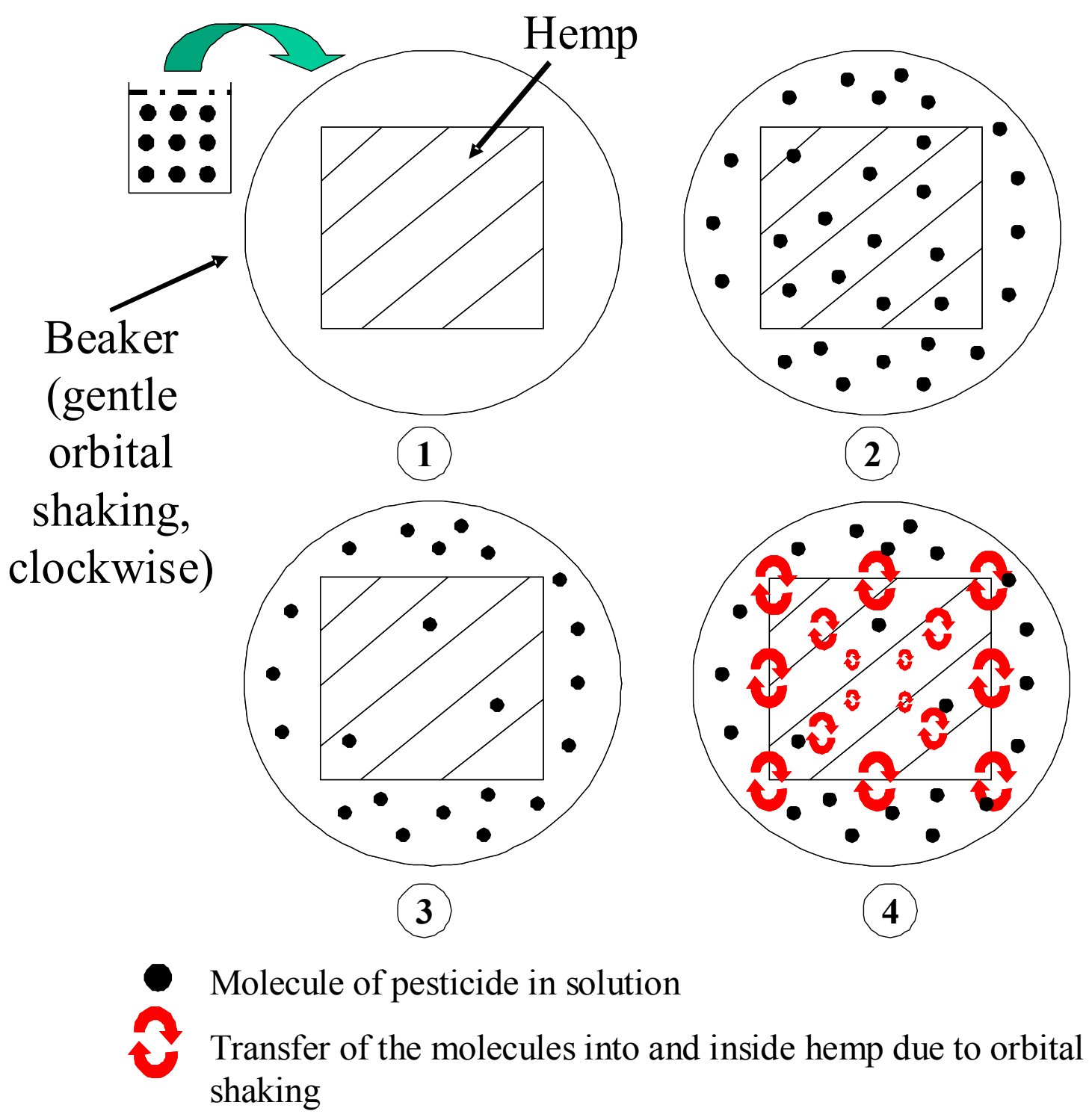

Figure 6. 

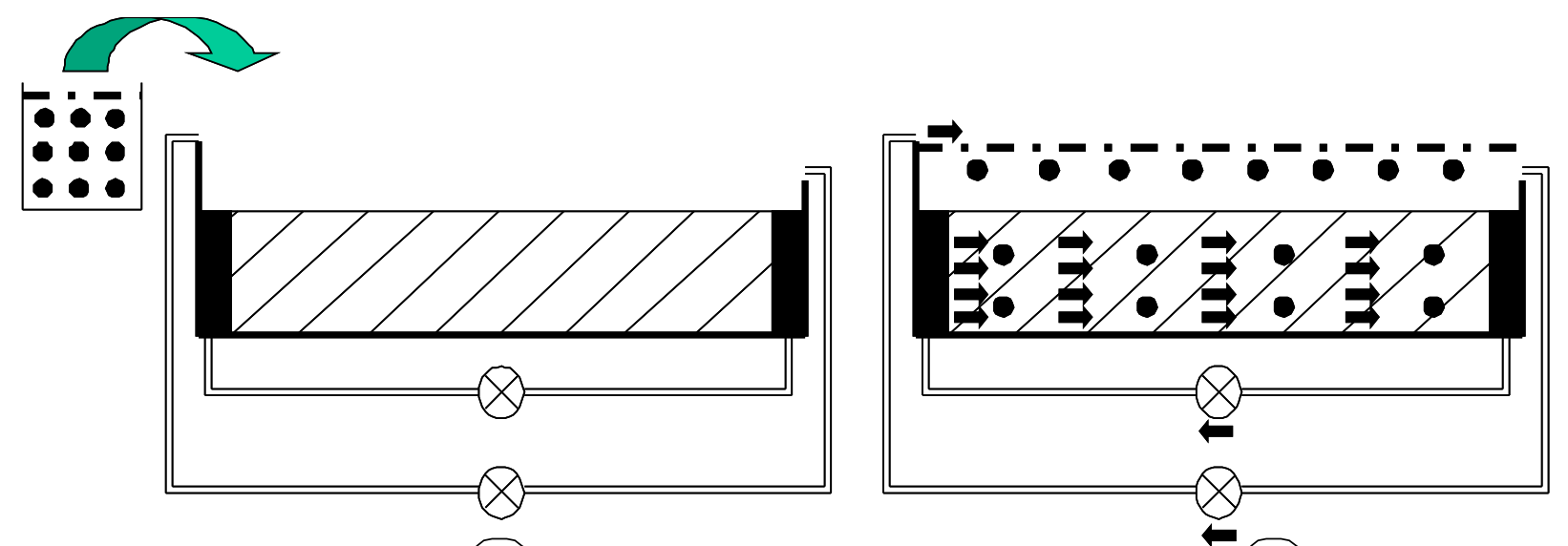

1
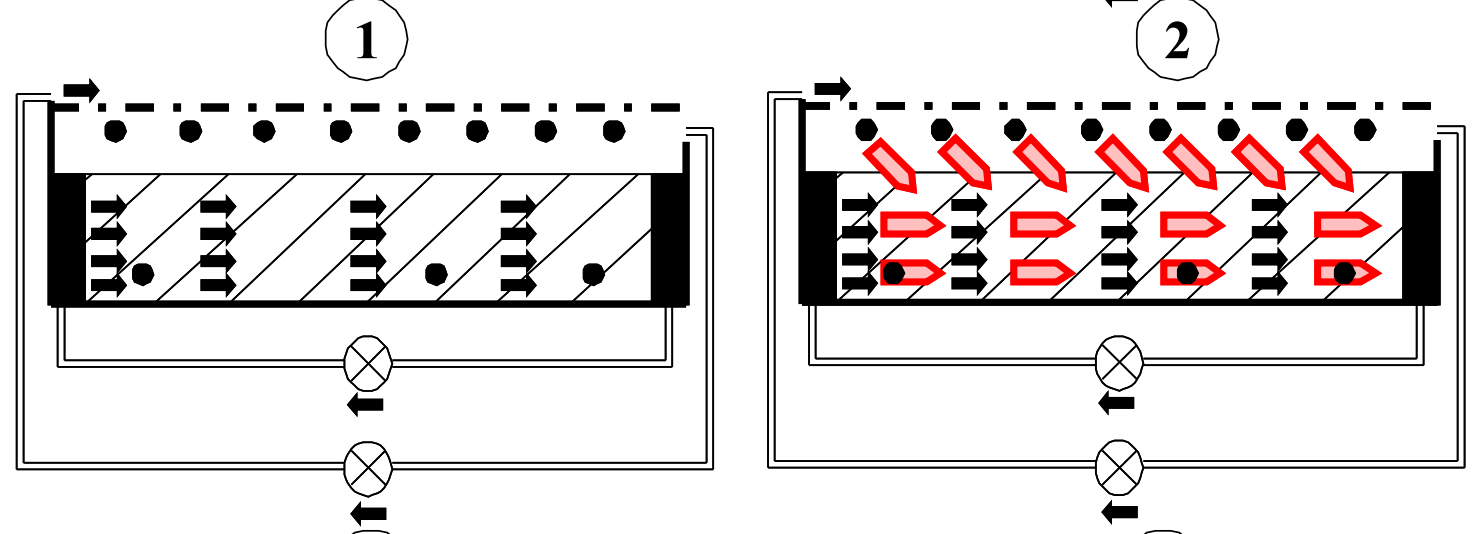

3

4

- Molecule of pesticide in solution

$\Rightarrow$ Water motion induced by the pumps

Transfer of the molecules of pesticide into and inside hemp, due to lateral movement induced by the pumps

Figure 7. 
(a): Diuron penetration in hemp initially saturated with water

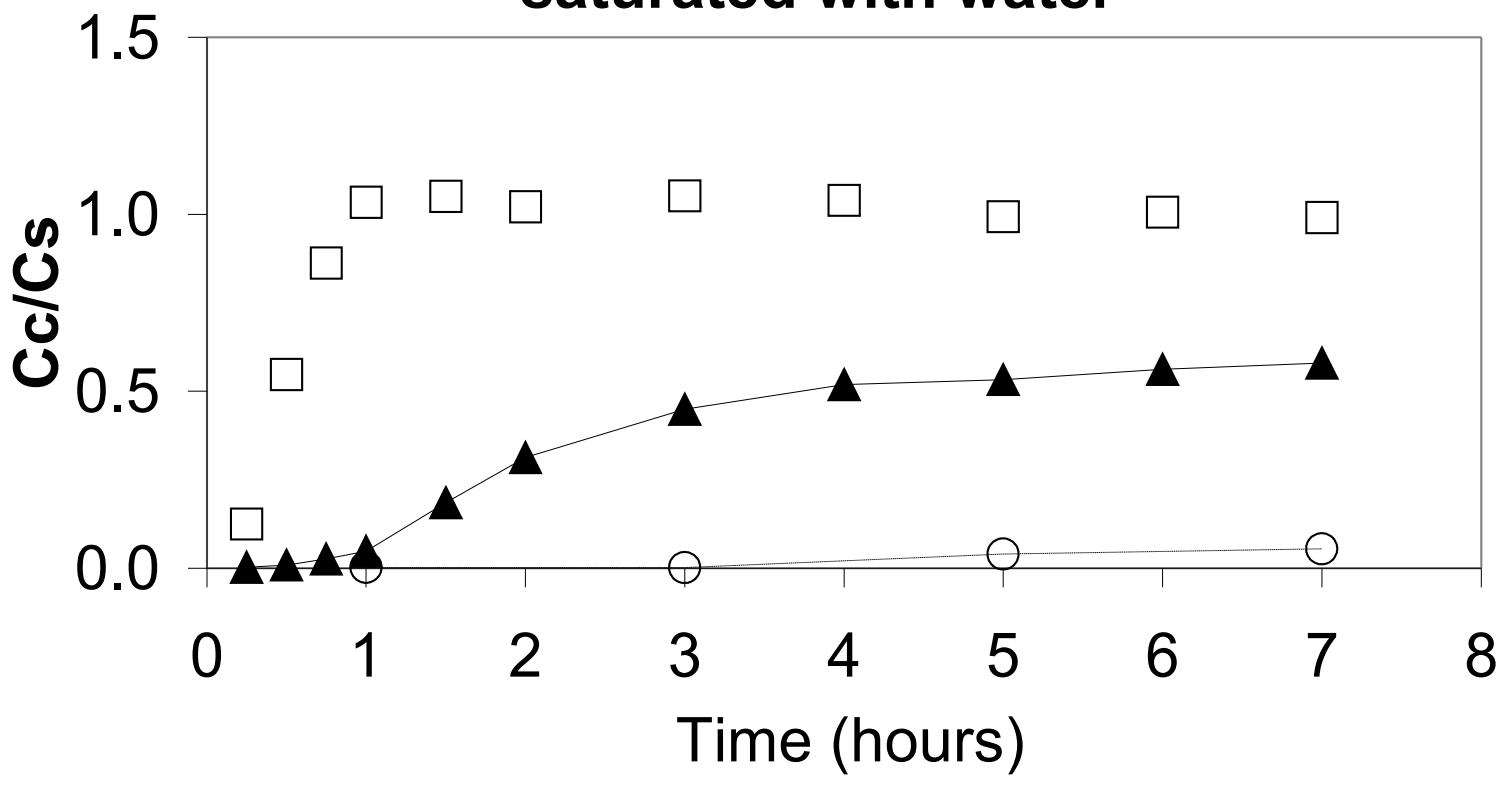

(b): Tebuconazole penetration in hemp initially saturated with water

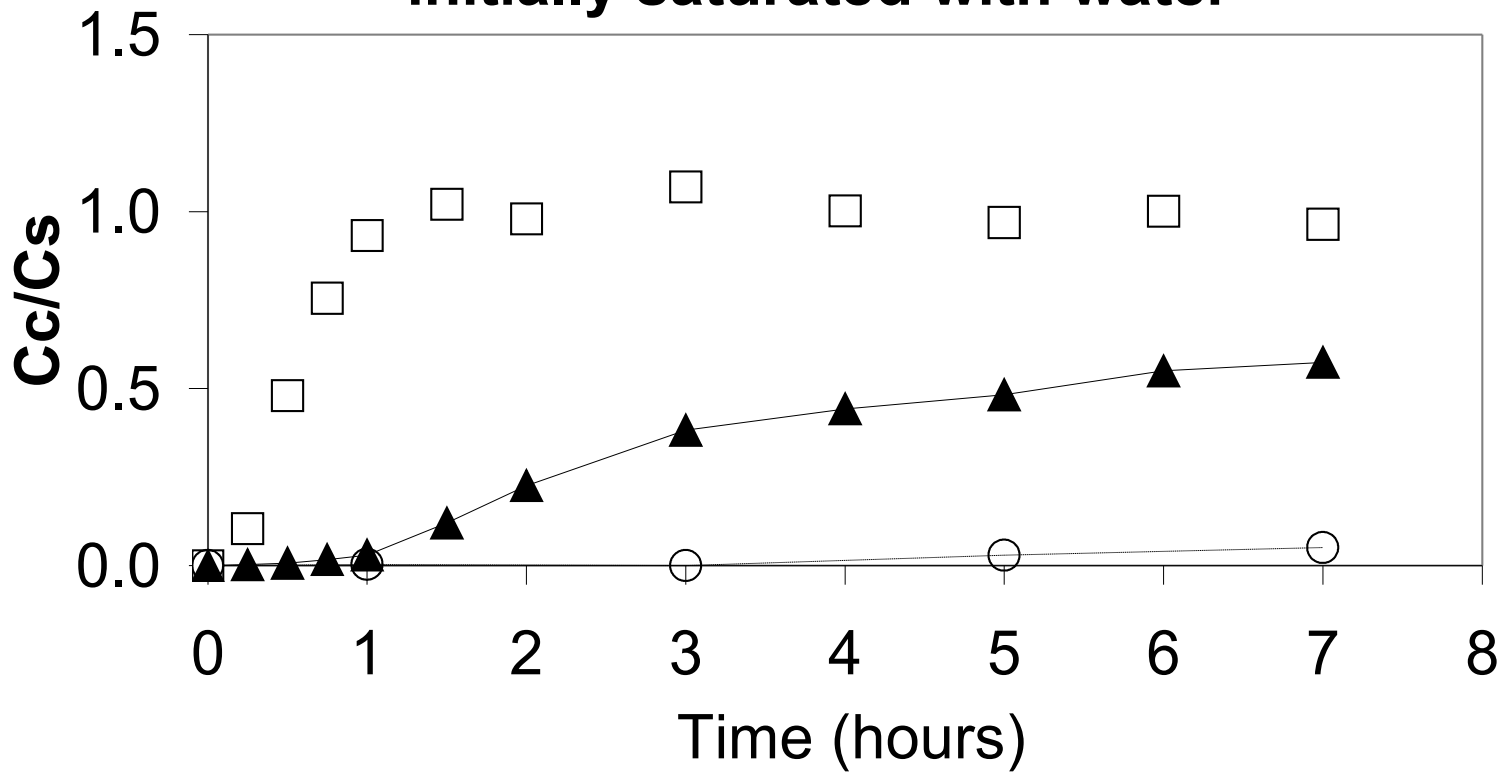

Figure 8. 
Table 1. Selected properties of the two pesticides considered in this work [22-24].

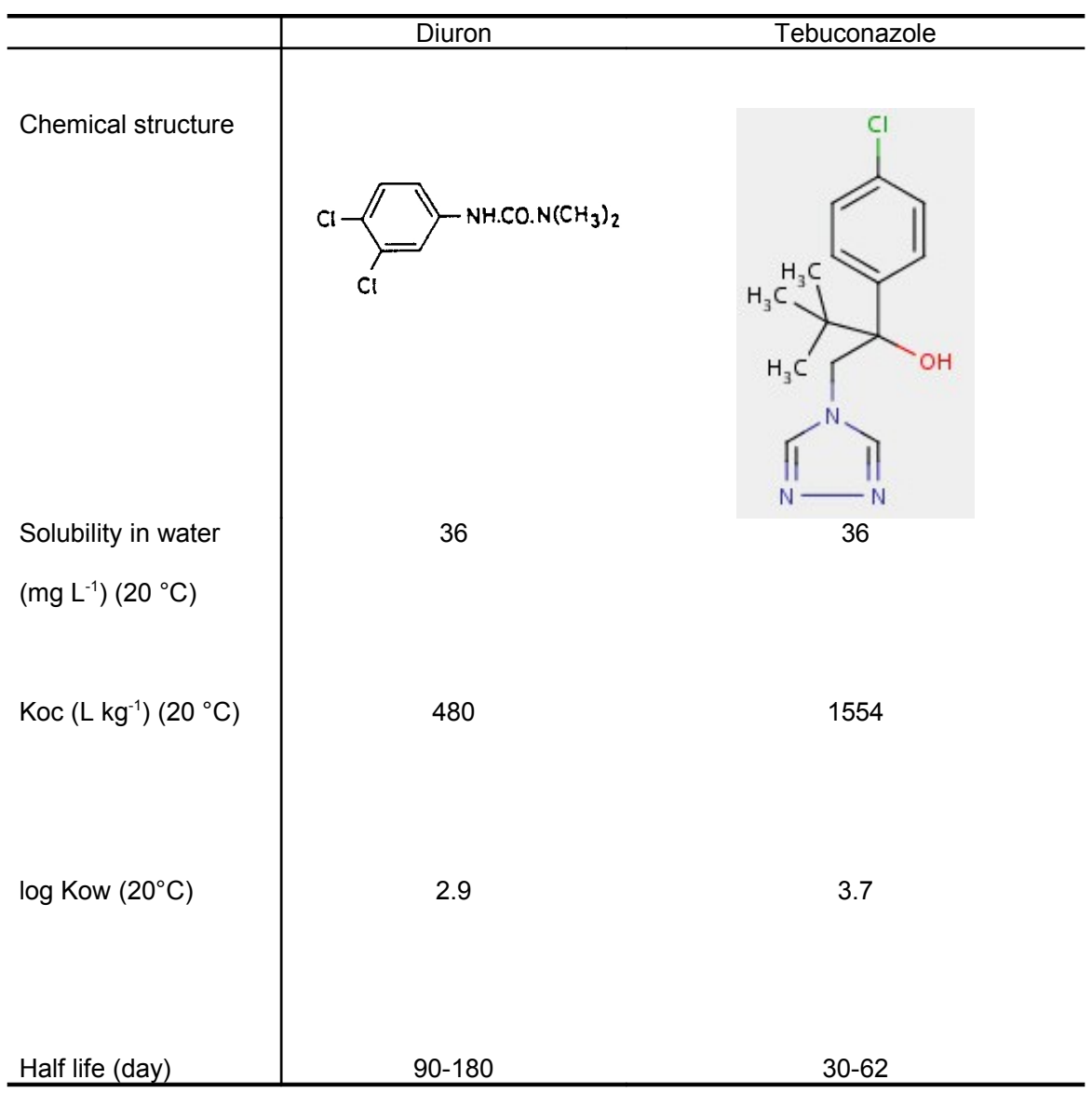


Table 2. Percentages of the mass of diuron and tebuconazole adsorbed onto hemp for the three experimental schemes after 7 or 24 hours (the results are expressed as percentages of the initial mass of pesticide in water at the beginning of the adsorption experiment).

\begin{tabular}{|c|c|c|c|c|}
\hline Pesticide & $\begin{array}{l}\text { Batch experiment } \\
\text { after } 7 \text { hours }\end{array}$ & $\begin{array}{c}\text { Batch experiment after } 24 \\
\text { hours (at equilibrium) }\end{array}$ & $\begin{array}{l}\text { Flume with initially dry } \\
\qquad \begin{array}{c}\text { hemp } \\
\text { after } 7 \text { hours (at } \\
\text { equilibrium) }\end{array}\end{array}$ & $\begin{array}{l}\text { Flume with initially saturated } \\
\text { hemp r } \\
\text { after } 7 \text { hours }\end{array}$ \\
\hline Diuron & 29 & 35 & 44 & 9 \\
\hline ebuconazole & 34 & 47 & 48 & 20 \\
\hline
\end{tabular}

